\title{
Educação para a sustentabilidade: horizontes na esperança de futuro
}

\author{
Sérgio Trombetta ${ }^{1}$
} Jaime José Zitkoski ${ }^{2}$

\section{Resumo}

A discussão central que se buscou desenvolver no presente artigo é a de que a educação ocupa lugar privilegiado no processo de construção de uma cultura sustentável, a qual requer a superação do paradigma antropocêntrico. Urgem mudanças radicais no estilo de vida em sociedade se quisermos evitar a destruição da vida. Nesse sentido, precisa-se caminhar na direção de um novo humanismo alicerçado na sabedoria, na simplicidade e na humildade. O desafio da educação é reconciliar o ser humano com a natureza e desenvolver o sentido de pertença, ternura e responsabilidade frente à vida. Para desenvolver essa ética do cuidado e da responsabilidade em relação à natureza, é imprescindível trabalhar o eu interior e desenvolver a consciência profunda de que somos dependentes da natureza. Eis aí a ecologia profunda, que requer de todos um encantamento amoroso, poético e místico frente à natureza. Essa transformação espiritual é essencial na caminhada em direção a uma cultura de convivência harmoniosa e pacífica com a Mãe Terra. Portanto, a tarefa no campo da educação é desenvolver um novo paradigma cultural, capaz de contemplar a sustentabilidade nas práticas sociais, políticas e econômicas, que tenha sempre no horizonte possível a justiça social, a democracia, a solidariedade, uma cultura da paz, o respeito à pluralidade e uma política global dos direitos humanos. Nosso futuro comum, na era da sociedade global, dependerá da nossa capacidade de desenvolver essa nova consciência, que busca a sustentabilidade em todas as dimensões de nossa existência.

Palavras-chave: Educação. Sustentabilidade. Ética. Política.

\section{Abstract}

The central thread which seek to develop in this article is that education occupies a special place in building a sustainable culture that requires overcoming the anthropocentric paradigm process. Urge radical changes in lifestyle in society if we are to avoid the destruction of life. In this sense, we need to move toward a new humanism rooted in the wisdom, simplicity and humility. The challenge of education is to reconcile human beings with nature and develop a sense of belonging,

\footnotetext{
${ }^{1}$ Professor de Antropologia e Ética na Universidade do Vale do Rio dos Sinos (Unisinos), São Leopoldo, RS e nas Faculdades Integradas de Taquara - Faccat, Taquara, RS. sergiot@unisinos.br

2 Professor de Filosofia da Educação na Faculdade de Educação (Faced)_e no Programa de PósGraduação de Educação da Universidade Federal do Rio Grande do Sul (UFRGS), Porto Alegre, RS. jaime.jose@ufrgs.br
} 
tenderness and responsibility towards life. To develop this ethic of care and responsibility toward nature is essential to work the inner self and develop a deep awareness that we are dependent on nature. Behold, deep ecology, which requires of us a loving, poetic and mystical enchantment toward nature. This spiritual transformation is essential in the journey toward a culture of harmonious and peaceful coexistence with Mother Earth. Therefore, our task in the field of education to develop a new cultural paradigm able to contemplate sustainability in social, political and economic practices, which always has the possible horizon for social justice, democracy, solidarity, a culture of peace, respect the plurality and global human rights policy. Our common future in the age of global society will depend on our ability to develop this new consciousness that seeks sustainability in all dimensions of our existence.

Keywords: Education. Sustainability. Ethics. Policy.

\section{0 atual contexto e os impactos da ação humana na natureza}

No que se refere à ecologia e à busca por sustentabilidade, o tempo presente é marcado por muitas crises e incertezas, mas também pelo aumento da consciência em relação à necessidade de encontrarmos alternativas para as consequências destrutivas à natureza e, ao mesmo tempo, pela sensibilidade ecológica traduzida na ética do cuidado.

A natureza deve ser preservada e não ser objeto apenas para satisfazer as necessidades materiais e estéticas da humanidade. Precisamos agir pensando nas gerações futuras e, ao mesmo tempo, com a consciência de que nossas pretensões de crescimento ilimitado se chocam com um inexorável princípio de realidade.

Nenhum crescimento infinito é possível no recinto finito da esfera terrestre. Devemos aprender a conviver com os recursos finitos do nosso planeta. Num mundo limitado, não pode existir um crescimento ilimitado. Nossas pretensões prometéicas de progresso e desenvolvimento são impossíveis e incompatíveis com a contingência da realidade (JUNGES, 2004, p. 107).

Essa preocupação com a sustentabilidade não pode ficar restrita à ética individual convertida em ações responsáveis, que levam em conta os efeitos dos nossos atos, mas se traduz também no avanço da legislação que visa proteger o meio ambiente.

Os governos, por sua vez, pressionados pelos movimentos sociais e pela sociedade civil, são obrigados a contemplar políticas ecológicas que visam à salvaguarda dos ambientes naturais. Aos poucos, adquire-se a consciência da 
vulnerabilidade da natureza e da sua infinita fragilidade. O nosso planeta pode morrer, os ecossistemas podem entrar em colapso e se tornarem hostis à continuidade da vida em equilíbrio. Por isso, é dever ético e político de todos aprender a cuidar da Terra.

À medida que os debates a respeito da sustentabilidade se aprofundam e envolvem cada vez mais pessoas, instituições e organizações da sociedade civil, percebemos que a solução dos problemas ecológicos é complexa. Aos poucos, percebemos que, sem uma mudança de paradigma, certamente não seremos capazes de encontrar alternativas razoáveis aos grandes desafios que a crise ecológica impõe à sociedade global: "A crise ecológica não significa apenas o surgimento de problemas ambientais, mas a necessidade de novas formas de enxergar o mundo e a natureza. Parece indispensável uma mutação cultural que supere a visão redutiva e alcance um enfoque mais global da natureza" (JUNGES, 2004, p. 51).

Com o avanço da crise, verifica-se que a solução não é somente técnica, mas ética, e envolve o desenvolvimento da consciência individual e coletiva de toda a sociedade em âmbito global. É necessário encontrar alternativas sustentáveis e, ao mesmo tempo, justas ao nosso estilo de vida, não é possível continuar no caminho que nos trouxe até aqui. A mudança não se limita ao modelo de produção de bens de consumo. É urgente uma mudança de rota na organização da vida econômica, das instituições políticas e nos hábitos pessoais.

Pode-se dizer que a crise ecológica aponta para a decadência do atual paradigma de intervenção no meio ambiente e de convivência entre os seres humanos, e destes com a natureza.

Além da destruição dos ecossistemas, percebe-se a dimensão social da crise ecológica. Falar em sustentabilidade implica formular críticas radicais ao paradigma antropocêntrico e à racionalidade instrumental moderna que visa unicamente o lucro sem levar em conta o meio ambiente, sua sustentabilidade presente/futura e a justiça social. As dificuldades ecológicas só serão equacionadas com a construção de uma sociedade justa e igualitária, onde a vida, em sentido amplo, seja valorizada e preservada.

Essa transformação profunda na matriz filosófica, antropológica e ética dos pilares da sociedade moderna, ancorada num projeto de conquista do 
mundo/natureza pelo viés econômico, ocupa um lugar central na discussão do tema da sustentabilidade. Não se trata de um discurso superficial, que fica restrito à simples denúncia. $\mathrm{O}$ que se busca de maneira imperativa é um novo paradigma de convivência que enfatiza a qualidade de vida em detrimento à quantidade de coisas. Esse novo olhar sobre a realidade, inspirado pela ecologia na perspectiva de uma sociedade sustentável, pretende superar a visão limitada e estreita da racionalidade instrumental atrelada ao imperialismo da produção, do lucro e do consumo como único projeto que dá sentido à nossa existência individual e coletiva.

A solução dos principais problemas do nosso tempo, nas diferentes esferas, passa pela mudança radical das nossas percepções, do nosso pensamento e dos valores que servem de base para as ações individuais e das instituições econômicas e políticas. Para Capra (1996), estamos no princípio de uma mudança radical de visão do mundo, na ciência e na sociedade, uma mudança de paradigma tão profunda como foi a revolução copernicana. É preciso rever grande parte dos conceitos e os esquemas mentais que organizam nossas relações com a natureza e com as pessoas. O conjunto de mudanças no estilo de pensar e de agir são essenciais para construir sociedades sustentáveis. Para o autor, uma sociedade sustentável é aquela que satisfaz suas necessidades sem diminuir as perspectivas das gerações futuras.

Este é o grande desafio do nosso tempo: criar comunidades sustentáveis, ambientes sociais e culturais onde podemos satisfazer as nossas necessidades e aspirações sem diminuir as chances das gerações futuras. Mas, para que isso se realize de modo efetivo, é urgente e fundamental mudar nossas atitudes, mudar as mentalidades, criar novos comportamentos, rever nosso estilo de vida, especialmente a ideologia do progresso ilimitado.

Na verdade, estamos em uma encruzilhada: se a humanidade quer viver, ela precisa mudar seu paradigma civilizacional e repensar a ideologia do crescimento material ilimitado.

\section{A insustentabilidade do modelo antropocêntrico de desenvolvimento}

Na ótica do modelo de desenvolvimento antropocêntrico, os recursos naturais, a natureza e seus ecossistemas estão à disposição do desfrute ilimitado dos seres humanos. Podemos usar os recursos naturais para promover o progresso material 
ilimitado. O que mais se deseja é a conquista, o controle da natureza e a busca insaciável de lucros sem limites. O paradigma antropocêntrico foi construído sobre a ideologia do progresso ilimitado.

Com o passar do tempo, e diante dos avanços na ciência e na tecnologia, nos tornamos vítimas de um verdadeiro mito do crescimento. Fomos hipnotizados pela ilusão de que é possível produzir riquezas, bens materiais sem levar em conta a lógica da natureza. É o modelo desenvolvimentista, onde o progresso material é colocado acima de tudo.

O dever moral é utilizar para proveito imediato e o mais rapidamente possível o máximo de recursos naturais disponíveis. Essa atitude moral acompanhou e justificou a conquista de terras selvagens e a sua colonização e exploração em vista do lucro e do enriquecimento (JUNGES, 2004, p. 11).

Essa é a ideologia do progresso, que motivou a expansão colonialista e é a base do capitalismo: produzir e ampliar os mercados, através da publicidade, da criação de necessidades e de novos desejos. Foi essa corrida por novos mercados fornecedores de matéria-prima e de consumidores, por exemplo, que impulsionou a Primeira Guerra Mundial.

O que está por trás dessa falácia do progresso capitalista é a crença do caráter ilimitado dos recursos naturais. Não há dúvidas de que a Revolução Industrial melhorou a vida dos seres humanos, mas também é verdade que o progresso industrial aprofundou o dualismo ser humano-natureza. Aos poucos percebe-se que é impossível um crescimento ilimitado a partir dos recursos finitos da natureza. Os interesses da sustentabilidade se chocam com a voracidade do ser humano e seu sonho de progresso linear sem respeitar os tempos da natureza, que são cíclicos.

\footnotetext{
Esse sonho de prosperidade ilimitada ocupa o imaginário coletivo da humanidade e formata a agenda central de qualquer governo. Ai da política econômica e tecno-científica que não apresentar anualmente índices positivos de crescimento. Mas esse sonho está se transformando num pesadelo, pois está levando os países, a humanidade, a Terra a um impasse fatal: os recursos são limitados, os ganhos não podem ser generalizados para todos, porque então deveríamos dispor de três Terras com os recursos da nossa, e a capacidade de regeneração do Planeta se encontra em estado crítico (BOFF, 2003, p. 15).
} 
$\mathrm{Na}$ concepção antropocêntrica, o ser humano é pensado como um ser superior em relação a todos os outros e sua missão é dominar a natureza e colocar ordem no caos. Tudo está centrado no ser humano, ao invés de estarmos junto dos demais seres, nos colocamos sobre e contra eles. Os seres humanos estão situados acima ou fora da natureza, como a fonte de todos os valores e a natureza tem um valor instrumental ou de uso.

O humano é visto como um Prometeu na aventura de controlar a natureza de acordo com os seus interesses. Somos hipnotizados pelo paradigma da conquista:

\begin{abstract}
Conquistar a Terra inteira, os oceanos, as montanhas mais inacessíveis e os recantos mais inóspitos. Conquistar povos e dilatar a fé e o império, eis o sonho dos colonizadores. Conquistar os espaços extraterrestres e chegar às estrelas, eis a utopia moderna. Conquistar o segredo da vida e manipular genes. Conquistar mercados e altas taxas de crescimento, conquistar mais e mais clientes e consumidores. Conquistar o poder do Estado e outros poderes como o religioso, o profético e o político. Conquistar e controlar os anjos e demônios que nos habitam. Conquistar o coração da pessoa amada, conquistar as bênçãos de Deus e conquistar a salvação eterna. Tudo e objeto de conquista. O que nos falta conquistar? (BOFF, 2003, p. 19-20).
\end{abstract}

Nessa visão que Boff (2003) denuncia acima, não há uma preocupação com as gerações futuras, pois o ser humano não é pensado como um ser que pertence à Terra e que depende dela em todos os aspectos físicos para sobreviver, mas é concebido como uma realidade descolada da natureza.

O antropocentrismo moderno suscita um ser humano 'prometéico' sempre mais auto-suficiente na satisfação de suas necessidades e confiante em suas próprias capacidades. Passa a imagem de força e de vitória sobre os condicionamentos, esquecendo sua indigência e dependência de muitos fatores para viver humanamente (JUNGES, 2004, p. 69).

Resgatar a dimensão da vulnerabilidade do ser humano é um passo essencial no desenvolvimento de uma nova ética de relação com a natureza. Apesar de todo progresso material, econômico e científico, o ser humano continua sendo um ser carente e frágil, que depende de outros e dos ambientes natural e social para viver.

\title{
3 Ecologia profunda: reconhecendo a teia da vida
}

Precisamos mudar nosso modo de pensar e sentir em relação ao meio ambiente, estabelecer uma relação emotivo-afetiva com a natureza, resgatar a 
noção de encantamento e dependência: o ser humano é natureza, a terra que pensa, canta, dança e se emociona.

$\mathrm{Na}$ ótica dos autores que pensam a questão da ecologia profunda, a crise ecológica com suas consequências vai muito além da questão ética, ela requer uma mudança dos paradigmas conceituais. O modo de perceber o mundo e de entender o lugar do ser humano nele deve mudar. Nessa ótica, o humano é pensado na sua radical dependência e relação afetiva com a natureza e a riqueza de ambientes que nos oferecem as condições necessárias para nos realizarmos na relação respeitosa com todas as formas de vida.

De acordo com Junges (2004), o modelo de ser humano compreendido como indivíduo isolado e separado do mundo, transformando a natureza em objeto que se encontra a seu dispor, cria patologias ambientais correspondentes a patologias psicológicas, pedagógicas e sociais. É necessário superar a concepção do ser humano como espécie dominante e separada do mundo, despojando-se do seu isolamento individualista e colocando-se no ponto de vista de todos. Trata-se de assumir uma perspectiva holística, adotando formas transpessoais em atitudes junto à natureza. Assim, emerge um ser humano ecológico em vez de egocêntrico, que se compreende essencialmente como ser em relação.

Uma visão adequada ao paradigma ecológico precisa superar a posição antropocêntrica centrada exclusivamente nos interesses humanos para chegar a uma compreensão ecossistêmica do ser humano que, de certo modo, está na origem da ética do cuidado.

O modelo de ecologia profunda preocupa-se com uma mudança radical do paradigma de percepção da natureza por parte do ser humano. O paradigma ecológico veio para superar o paradigma moderno da arrogância humana, da existência solipsista, da aventura de conquista e do domínio da natureza pela ciência e pela técnica, do uso desmedido e do desfrute imprudente dos recursos naturais; por fim, questionar a dicotomia entre o regime da natureza e o regime da sociedade de produção e consumo ilimitado, a perspectiva da ética procedimental e utilitarista.

Deve-se desenvolver a consciência de que o ser humano é natureza, que ele precisa da natureza para se desenvolver. Nesse sentido, a natureza não pode servir apenas aos interesses humanos. É urgente superar o modelo de competição e 
introduzir uma cultura de cooperação, de solidariedade, capaz de harmonizar o ser humano e a natureza.

A ecologia profunda insiste na necessidade de mudanças profundas tanto no modo de nos relacionarmos com a natureza como no de organização da economia. Na ótica de Capra (1996), a ecologia profunda não separa seres humanos - ou qualquer outra coisa - do meio ambiente natural. Ela vê o mundo não como uma coleção de objetos isolados, mas como uma rede de fenômenos que estão fundamentalmente interconectados e são interdependentes. A ecologia profunda reconhece o valor intrínseco de todos os seres vivos e concebe os seres humanos apenas como fio particular na teia da vida. Em última análise, a percepção da ecologia profunda é a percepção espiritual ou religiosa.

Quando a concepção de espírito humano é entendida como o modo de consciência no qual o indivíduo tem uma sensação de pertinência, de conexidade com o cosmos como um todo, torna-se claro que a percepção ecológica é espiritual na sua essência mais profunda.

\section{A ética do cuidado: educar para a sensibilidade e o respeito à vida}

A chamada modernidade proporcionou avanços significativos em todas as áreas, especialmente na científica e na tecnológica. Do ponto de vista material, houve conquistas que nos surpreendem, mas, no que se refere à vida espiritual, ética e afetiva, a sensação é que nos encontramos frente a uma defasagem moral muito grande.

Para alguns autores, a humanidade regrediu moralmente, não conseguimos desenvolver uma ética capaz de administrar a complexidade da era tecnológica. A autossuficiência tecnológica e científica, o gigantesco progresso na área da informática e a robótica contrastam com o vazio existencial, a fragilidade psíquica, o tédio e a desorientação de muitas pessoas na sociedade atual.

Podemos afirmar que a modernidade tornou o ser humano mais vulnerável em sua interioridade. Como nos diz Morin e Kern (2005), há uma miséria que não diminui com o decréscimo da miséria fisiológica e material, mas que aumenta com a abundância e o lazer. Há certamente uma penúria afetiva e psíquica, em maior ou menor grau, em todas as civilizações e em toda parte há um grave 
subdesenvolvimento do espírito humano, é preciso ver a miséria mental das sociedades ricas e a escassez de amor nas sociedades de fartura.

É algo imperioso enfrentar a miséria mental, o atrofiamento ético, a crise de sensibilidade e de compaixão. Enquanto formos mentalmente subdesenvolvidos, aumentaremos a barbárie exterior. Enfrentar os atrasos, essa pobreza mental, psíquica, afetiva, ética, estética é chave no caminho da ética do cuidado e, ao mesmo tempo, na construção de uma cultura alicerçada na justiça e no respeito aos direitos humanos.

Para Boff (1999), diante da crise ecológica e civilizacional, tornou-se urgente desenvolver nas pessoas, nas instituições e na atividade política o modo de ser do cuidado. Quando amamos, cuidamos e, quando cuidamos, amamos. Por isso, o ethos que ama se completa com o ethos que cuida. O cuidado constitui a categoria central do novo paradigma de civilização que tenta emergir em todas as partes do mundo: ou cuidamos, ou perecemos. O cuidado pertence à presença humana no mundo, nossa presença no mundo é marcada pelo cuidado. O ser humano é fundamentalmente um ser de cuidado e de sensibilidade. Sem a dimensão do cuidado a vida fica exposta a muitas ameaças. O cuidado previne danos futuros e regenera os danos passados. É o ethos do cuidado que nos permite resistir a todas as formas de violência e agressões contra a vida, ele constitui nossa verdadeira essência e deve nos acompanhar a vida inteira: "A consciência da fragilidade da própria vida, exigindo desvelo, leva o ser humano a dar-se conta de que a vida, pulsando no seu entorno natural e animada por inter-relações vitais, é também frágil, necessitada de solicitude e cuidado" (JUNGES, 2004, p. 82).

O papel do ser humano não é apropriar-se da natureza como um senhor que a escraviza pensando somente no seu bem estar - crescimento material ilimitado, exploração de todos os recursos oferecidos por ela - mas cuidar da natureza na perspectiva da sustentabilidade, da conservação das suas belezas. A vida é um milagre da natureza. Por isso, nossa atitude ética deve ser a do cuidado com todos os seres vivos.

Sem o cuidado de todos os elementos que compõe a vida, o próprio Planeta Terra, o desenvolvimento necessário e a sustentabilidade não teriam condições de se firmar e se consolidar. Por isso, não se pode dissociar sustentabilidade do cuidado: ambos formam as duas pilastras que sustentarão um novo ensaio civilizatório, com seu tipo de desenvolvimento e sua forma de conviver neste pequeno planeta junto com todos os seres e com a comunidade de vida (BOFF, 2012, p. 93-94). 
Para adotar a atitude de cuidado, o ser humano precisa se sentir parte da natureza, fazer uma experiência mística, espiritual, profunda, aceitando que ele também é natureza. O ethos do cuidado serve de crítica à nossa civilização agonizante e também de princípio inspirador de um novo paradigma de convivência ancorado na democracia e na justiça social.

\begin{abstract}
Quem não está aberto a ouvir o grito dos pobres não terá condições de auscultar o grito da natureza, porque falta sensibilidade pelo gemido do pulsar da vida. Cuidado solidário pelos deserdados humanos educa e sensibiliza pelo cuidado respeitoso de todo ser vivo. A degradação da Terra em sua biosfera e nas formas de vida que a povoam é o reverso da medalha do aviltamento do rosto de seres humanos reduzidos à pura sobrevivência (JUNGES, 2004, p. 104).
\end{abstract}

Para que o cuidado torne-se uma atitude básica, o ser humano precisa se sentir e estar inserido ou integrado em uma teia, dependendo dos mesmos fatores que possibilitam a vida dos outros animais. A ética do cuidado não se limita ao cuidado da natureza, ela amplia seu olhar para a nossa vida em sociedade e se preocupa com a dimensão social.

\title{
5 Alfabetização ecológica: possibilidades para uma cultura sustentável
}

Frente à crise ecológica, é essencial adotar uma visão sistêmica e pensar a economia tendo em vista a limitação dos recursos naturais. Precisamos nos tornar ecologicamente alfabetizados e entender os princípios básicos de organização das comunidades ecológicas: "Alfabetização ecológica significa uma mudança do paradigma cultural que regeu as relações entre os seres humanos e a natureza nos últimos quinhentos anos. Esse câmbio cultural só é possível pela conversão moral das atitudes de consumo e convivência vigentes" (JUNGES, 2004, p. 109).

O objetivo central da Alfabetização Ecológica é aprender a viver de modo sustentável, aprender a viver em equilíbrio com a natureza e compreender o funcionamento sistêmico da natureza é parte importante nesse processo de alfabetização. Na natureza, tudo é relação, parceria, interdependência, diversidade. Os processos são cíclicos e não lineares e há equilíbrio nos ecossistemas. Aplicar esses princípios às comunidades humanas significa pensar a democracia, a justiça social, a cooperação, a solidariedade, a diversidade cultural. Por exemplo, a 
economia enfatiza a competição, a expansão e a dominação, enquanto que a ecologia enfatiza a cooperação, a conservação e a parceria.

$\mathrm{Na}$ sabedoria da natureza, há um equilíbrio de modo a garantir a continuidade da vida, por exemplo, não há o acúmulo de recursos ou injustiças. Nesse sentido, podemos dizer que a sobrevivência da humanidade dependerá de nossa alfabetização ecológica, da nossa capacidade para entender que precisamos administrar os recursos limitados da natureza e adotar a ética do cuidado. O ser humano é parte implícita do mundo natural, sua existência condiciona-se ao equilíbrio da natureza, por isso, devemos adotar atitudes de preservação e conservação de todos os ecossistemas que viabilizam nosso existir na perspectiva de uma qualidade de vida entendida como convivência respeitosa com a natureza.

A situação em que nos encontramos exige uma educação direcionada para uma vida/cultura sustentável. Como nunca antes na história, o nosso futuro comum nos conclama a buscar um novo paradigma de convivência e de relação dos humanos entre si e também em relação à natureza. São urgentes transformações profundas em nossa mente e nas ações individuais e coletivas.

Nesse sentido, é importante promover a crítica ao paradigma antropocêntrico e introduzir um diálogo a respeito da necessidade de um modelo de saber condizente com a sustentabilidade. A educação converte-se num processo estratégico, com o propósito de formar os valores, habilidades e capacidades para orientar a transição para a sustentabilidade (LEFF, 1998, p. 237). Precisamos educar para uma nova ética que oriente os valores e comportamentos sociais para os objetivos de sustentabilidade ecológica, de vida democrática, de respeito à diversidade cultural e de justiça social.

A sustentabilidade se opõe a tudo o que sugere desequilíbrio, competição, conflito, ganância, individualismo, domínio, destruição, expropriação e conquistas materiais indevidas e desequilibradas em termos de mudança e transformação da sociedade e do ambiente.

$\mathrm{Na}$ construção de um modelo de sociedade sustentável, devemos educar para a cooperação e a solidariedade, superando a ideologia da competição, do eu triunfante sobre os demais. Desenvolver também nas pessoas uma utopia e um senso de justiça que nos impulsione a lutar a favor de outro modelo de sociedade, com menos exclusão e contradições sociais, pois nunca se cresceu tanto 
economicamente, mas também nunca aumentaram tanto, em termos globais, a pobreza, a destruição de tecidos sociais, as crises políticas, as crises ambientais, a violência e o terror. Justiça social e sustentabilidade andam juntas, uma não existe sem a outra. Uma cultura sustentável deve nos levar a selecionar o que é realmente sustentável em nossas vidas e na dos outros, precisamos lutar por uma justiça social que combine com a justiça ecológica, com a democracia, os direitos humanos, a diversidade cultural e as relações pacíficas entre as pessoas e os diferentes povos.

Na construção de sociedades sustentáveis, é importante lutar e resistir contra a globalização econômica com sua agenda exclusivamente monetarista: "A globalização mata a noção de solidariedade, devolve o homem à condição primitiva do cada um por si e, como se voltássemos a ser animais da selva, reduz as noções de moralidade pública e particular a um quase nada" (SANTOS, 2000, p. 65).

Para fazer frente às consequências desumanas da globalização capitalista, é imperativo pensar políticas locais: "Nesse nosso mundo que se globaliza, a política tende a ser - cada vez mais apaixonada e conscientemente - local, encontrar soluções globais para contradições globais" (BAUMAN, 2009, p. 30). As políticas estão cada vez mais locais num mundo estruturado por processos cada vez mais globais, por isso é preciso pensar globalmente e agir localmente. Na era global, parece possível fazer ambas as coisas: pensar e agir global e localmente, sem dicotomizá-las.

Não se pode falar em vida sustentável sem pensar uma cidadania política e social em esfera planetária. Sem uma concertação global, os problemas do meio ambiente não serão solucionados:

\footnotetext{
A globalização em si não é problemática, pois representa um processo de avanço sem precedentes na história da humanidade. O que é problemático é a globalização competitiva, na qual os interesses dos povos se subordinam aos interesses corporativos das grandes empresas transnacionais. Assim, podemos distinguir uma globalização competitiva de uma possível globalização cooperativa e solidária. A primeira está subordinada apenas às leis do mercado e a segunda, aos valores éticos e à espiritualidade humana (GADOTTI, 2000, p. 153).
}

Para que se chegar a uma sociedade/cultura sustentável, faz-se necessário pensar o desenvolvimento pessoal pela via do aperfeiçoamento espiritual. A ecologia do eu é o ponto de partida para enfrentar a crise em que nos encontramos, é o educar para o ser, mais ais expansão interior e menos necessidade de consumir. A 
necessidade imperiosa de consumir será substituída por um projeto de desenvolvimento espiritual: menos ter e mais ser.

A transformação pessoal na esfera interior ocupa lugar central na luta por uma cultura sustentável: "As pessoas e o planeta precisam ser salvos no mesmo projeto de futuro da própria humanidade" (GADOTTI, 2000, p. 158). O cuidado pelo eu e o cuidado com o planeta não são excludentes. A ética do desenvolvimento pessoal salvará o eu da alienação, que faz do eu um consumidor compulsivo e provoca a morte do planeta.

De acordo com Morin e Viveret (2013), quanto mais estressados, competindo, confusos, mergulhados na destruição ecológica, na rivalidade com o outro, na ausência de serenidade, mais a publicidade nos faz sonhar com um desenvolvimento na ordem do ser, da felicidade, da amizade, da serenidade, da beleza... com um duplo efeito perverso.

Para começar, segundo a lógica toxicômana, uma pessoa que acredita nessa promessa de desenvolvimento na ordem do ser e aceita a mensagem subliminar: para progredir na ordem do ser, acelere seu crescimento na ordem do ter, essa pessoa, inevitavelmente, vai se deparar, mais cedo ou mais tarde, com uma situação de decepção e frustração e a mensagem poderá dizer que é porque ela não tomou a dose de cuidado necessária.

Em seguida, tem-se o segundo efeito perverso, o "sempre mais" do hiperconsumo dispara a escassez artificial em certos casos. Vale lembrar a famosa frase de Ghandhi (citada por Gadotti, 2000, p. 23): "existem em nosso planeta recursos suficientes para atender às necessidades de todos, mas em compensação eles não bastarão se o objetivo for satisfazer o desejo de posse, a avidez, a cobiça, mesmo que seja de apenas alguns".

A miséria material de uns está diretamente relacionada à miséria ética, afetiva e espiritual de outros. As grandes transformações começam na consciência e no coração de cada um, pois não é possível sonhar com revoluções sem antes libertar a consciência. De acordo com Capra (1996), fluem unidas uma consciência ecológica e uma consciência espiritual profunda.

A cultura da sustentabilidade passa necessariamente pelo aprimoramento da vida interior, pela ética que cuida da vida e se preocupa com a justiça social estendida a todas as pessoas. Somente uma revolução espiritual radical, profunda, 
pode ser fonte de inspiração para caminharmos na direção de uma cultura da sustentabilidade: "A lógica de uma sociedade fundamentada em produtos deve dar lugar a outro tipo de lógica que se preocupa muito mais pelo crescimento das pessoas que pela produção e acumulação" (GUTIÉRREZ; PRADO, 2000, p. 76). A sociedade consumista não é só perturbadora da ordem natural e social, ela causa muitos estragos à ecologia mental.

\section{Considerações finais}

A educação ambiental tem papel estratégico na construção das condições culturais e éticas para a efetivação de uma sociedade sustentável. A sustentabilidade será produto da sociedade global, ou não acontecerá. Precisamos adotar um estilo de vida mais simples, viver com mais sabedoria e não buscar a felicidade somente no consumo e no apego aos bens materiais.

No atual momento da nossa civilização, uma educação para a sustentabilidade deve trabalhar a sensibilidade com o planeta, o cuidado, a solidariedade, e incluir um projeto de mundo com dignidade para as gerações futuras.

O desafio é buscar um novo paradigma alicerçado na sustentabilidade, na cultura de respeito aos direitos humanos, na justiça social e na democracia. Mas, para que isso aconteça, é imprescindível uma mudança nas estruturas econômicas, sociais, culturais e especialmente na ecologia mental de todas as pessoas. É necessário mudar os pensamentos, as instituições e as ações. Nesse projeto, a educação é peça chave, pois é um espaço da formação humana e da cidadania.

Precisa-se agir com responsabilidade, sensibilidade e ética para promover essas mudanças paradigmáticas, sem despolitizar o diálogo em favor de uma sociedade sustentável, sem uma mudança interior (progresso intelectual, espiritual, afetivo e ético) das pessoas, é possível afirmar que não obteremos sucesso nesse processo de transformação alicerçada na perspectiva da cultura da sustentabilidade.

No último século, promovemos revoluções políticas, econômicas e tecnológicas, mas não aprimoramos a ética e a dimensão espiritual nas pessoas. $O$ que se faz necessário, sem esquecer as mudanças materiais e exteriores, é uma revolução espiritual que tenha ressonância nas ações cotidianas, pois, como nos diz 
Paulo Freire (1995): "A educação não muda o mundo, mas muda as pessoas que vão mudar o mundo".

\section{Referências}

BAUMAN, Zygmunt. Confiança e medo na cidade. Rio de Janeiro: Zahar, 2009.

BOFF, Leonardo. Ética e moral: a busca dos fundamentos. Petrópolis: Vozes, 2003. 1999. . Saber cuidar: Ética do humano - compaixão pela terra. Petrópolis: Vozes, . Sustentabilidade: o que é - o que não é? Petrópolis: Vozes, 2012.

CAPRA, Fritjof. A Teia da Vida. São Paulo: Cultrix, 1996.

FREIRE, Paulo. À sombra desta mangueira. São Paulo: Olho D’água, 1995.

GADOTTI, Moacir. Pedagogia da Terra. São Paulo: Peirópolis, 2000.

GUTIÉRREZ, Francisco; PRADO, Cruz. Ecopedagogia e Cidadania Planetária. São Paulo: Cortez; Instituto Paulo Freire, 2000.

JUNGES, José Roque. Ética Ambiental. São Leopoldo: Unisinos, 2004.

LEFF, Enrique. Saber Ambiental: sustentabilidade, racionalidade, complexidade, poder. Petrópolis: Vozes, 1998.

MORIN, Edgar; KERN, Anne-Brigitte. Terra-Pátria. Porto Alegre: Sulina, 2005.

MORIN, Edgar; VIVERET, Patrick. Como viver em tempo de crise?.Rio de Janeiro: Bertrand Brasil, 2013.

SANTOS, Milton. Por uma outra globalização - do pensamento único à consciência universal. Rio de Janeiro: Record, 2000. 